\title{
THE 2011 ECO3D FLIGHT CAMPAIGN: VEGETATION STRUCTURE AND BIOMASS ESTIMATION FROM SIMULTANEOUS SAR, LIDAR AND RADIOMETER MEASUREMENTS
}

\author{
Temilola Fatoyinbo ${ }^{l}$, Rafael Rincon ${ }^{1}$, David Harding ${ }^{1}$, Charles Gatebe ${ }^{1,2}$, Kenneth Jon Ranson , \\ Guoqing Sun ${ }^{3}$, Phillip Dabney ${ }^{1}$, Miguel Roman ${ }^{\prime}$, \\ ${ }^{1}$ NASA Goddard Space Flight Center, Greenbelt, MD, USA \\ ${ }^{2}$ Universities Space Research Association, Columbia, MD, USA \\ 3 University of Maryland, College Park, MD, USA
}

\begin{abstract}
The Eco3D campaign was conducted in the Summer of 2011. As part of the campaign three unique and innovative NASA Goddard Space Flight Center airborne sensors were flown simultaneously: The Digital Beamforming Synthetic Aperture Radar (DBSAR), the Slope Imaging Multi-polarization Photon-counting Lidar (SIMPL) and the Cloud Absorption Radiometer (CAR). The campaign covered sites from Quebec to Southern Florida and thereby acquired data over forests ranging from Boreal to tropical wetlands. This paper describes the instruments and sites covered and presents the first images resulting from the campaign.
\end{abstract}

Index Terms - DBSAR, SIMPLE, CAR, Biomass, multisensor

\section{INTRODUCTION}

Quantifying the carbon cycle is the most important element in understanding climate change and its consequences, yet is poorly understood (Le Toan et al, 2004). Forests store $85 \%$ of terrestrial carbon, yet the amount of carbon contained in the earth's forests is not known to even one significant figure, ranging from 385 to $6501015 \mathrm{~g}$ carbon (Goodale et al. 2002, Houghton et al. 2009).

Recent publications on $3 \mathrm{D}$ vegetation structure measurements have reiterated the urgent need of developing new spaceborne sensors capable of three dimensional structure measurements to understand changes and trends in terrestrial ecosystem function as carbon sources and sinks, and to characterize the impact of their changes on climate, habitat and biodiversity. In particular, the authors concluded that lidar profile samplers in combination with Lband polarimetric SAR data and ecosystem modeling can be used to satisfy the vegetation $3 \mathrm{D}$ structure and biomass measurement requirements (Hall et al. 2011).

These measurements of terrestrial biomass and ecosystem structure have far ranging societal, policy and management implications. The anticipated economic and societal burden that will result from unmitigated rises in $\mathrm{CO} 2$ emissions and losses in ecosystem services alone are estimated to be in the trillion of dollars by mid-century (Stern Report, 2008). Ongoing international carbon mitigation initiatives, such as the UNFCCC's Agreement on Reduced Emissions from Deforestation and Degradation (REDD + ) need detailed, precise and accurate measurements of carbon storage in terrestrial and coastal ecosystems to be successful.

Here were present a recent NASA effort towards acquiring these critical measurements with three unique and innovative NASA Goddard Space Flight Center airborne sensors that were flown as part of the Eco3D measurement campaign in August-September of 2011: The L-band Digital Beamforming Synthetic Aperture Radar (DBSAR), the Slope Imaging Multi-polarization Photon-counting 
Lidar (SIMPL) and the Cloud Absorption Radiometer (CAR), capable of bidirectional reflectance (BRDF) measurements.

\section{METHODOLOGY}

As a step towards getting multisensor fusion forest structure data, the unique and innovative DBSAR, SIMPL and CAR sensors were flown as part of the Eco3D measurement campaign in August and September 2011.

DBSAR is a digital beamforming L-band Synthetic Aperture Radar (SAR) that will provide critical information on vegetation structure needed to estimate vegetation biomass. Digital beamforming permits the implementation of non-conventional measurement techniques, which can overcome fundamental limitations of conventional radar systems (Krieger et al., 2008; Yunis et al. 2003) such as increasing the measurement swath without reducing the received antenna gain, suppressing ambiguities or localized interference in the receiver signal and synthesizing multiple beams on both sides of the aircraft using a single nadir-looking antenna (Rincon et al.; 2011A, 2011B, 2010).

SIMPL is a multi-beam, micropulse, single photon ranging laser altimeter that provides measurements of forest canopy structure with very high spatial resolution and dual-wavelength polarimetry data that can be used to differentiate stand types. It incorporates a variety of advanced technologies to demonstrate measurement approaches of potential benefit for more efficient spaceflight laser altimeter missions including ICESat-2. It acquires profile data using four closely-spaced, nadir-directed laser beams and provides a unique combination of capabilities.

CAR is an airborne multi-wavelength scanning radiometer that can measure spectral directional reflectance over uniform forests, homogenous clouds, and bright targets. The CAR instrument is an airborne multi-wavelength scanning radiometer that measures scattered light in fourteen spectral bands between 0.34 and 2.30 $\mu \mathrm{m}$. The CAR scan mirror rotates $360^{\circ}$ in a plane perpendicular to the direction of flight and the data are collected through a $190^{\circ}$ aperture that allows observations of the earth-atmosphere scene from local zenith to nadir.

One of the strength of this instrument is its unique ability to measure almost simultaneously, both downwelling and upwelling radiance at 14 narrow spectral bands located in the atmospheric window regions of the UV, visible, and nearinfrared. (Gatebe et al., 2003, 2005;2011; Lyapustin et al., 2010, Román et al., 2011).

The main science objectives of the Eco3D flight campaign were:

i. To acquire coordinated active (lidar and radar) and passive (radiometer) data over forest ecosystems,

ii. To evaluate methods for improved estimation of forest biophysical properties using these complimentary data,

iii. To measure the 3D structure of temperate and subtropical forests, and

iv. To measure above ground biomass and carbon storage in forest ecosystems ranging from boreal to subtropical wetlands.

The Flights onboard the NASA P3-B aircraft were conducted over areas of forests from Quebec, Canada to Florida, USA (Table 1). The sites were selected to provide a variety land cover types with recent ground measurements. As a result, the Eco3D measurements represent a comprehensive multi-sensor data set over diverse, well-characterized forest sites.

\begin{tabular}{ll}
\hline State & Name of Site \\
\hline Quebec & - Parc des Laurentides \\
& - Foret Montmorency \\
& - Parc de la Jacques-Cartier \\
Maine & - Howland Forest \\
New & Bartlett and Hubbard Brook \\
Hampshire & $\quad$ Forests \\
Pennsylvania & - Hickory Run \\
Maryland & - Wallops Flight Facility \\
and Virginia & - Smithsonian Ecological Research \\
& $\quad$ Center \\
\hline $\begin{array}{l}\text { North } \\
\text { Carolina }\end{array}$ & Parker Track \\
Florida & - Everglades National Park \\
\hline
\end{tabular}

Table 1 Field Sites covered by Eco3D data 


\section{RESULTS}

Figure 2 shows the high vertical and spatial resolution of canopy structure that is obtained by the advanced technology SIMPL instrument. A single-photon point at Howland, Maine documents structure at tree-crown scales. The range histograms that aggregate photons acquired over distances of $25 \mathrm{~m}$ reveal the canopy layers with meter-level vertical resolution. The profile location, in yellow is shown on a natural-color, nadir video image acquired in-flight. The low noise level is indicated by the count rate below the ground.

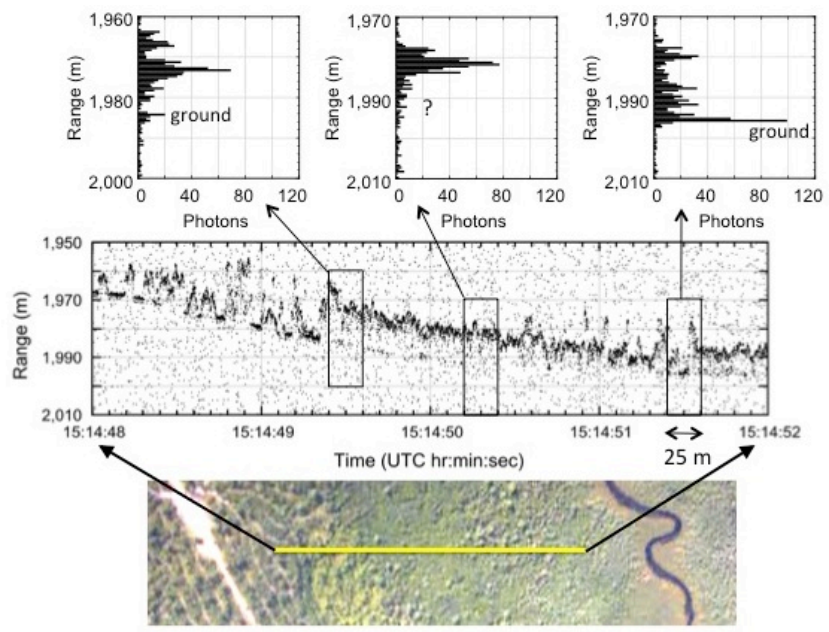

Figure 1 SIMPL profile from Howland, Maine acquired during Eco3D in 2011

The DBSAR measurements provide critical information on vegetation structure needed to estimate vegetation biomass and structure. During the Eco3D campaign, DBSAR acquired polarimetric data in repeat-pass and single-pass interferometric SAR modes at different heights. Figure 2 shows a DBSAR polarimetric RGB composite of the Howland, Maine site with the associated tha field plots.

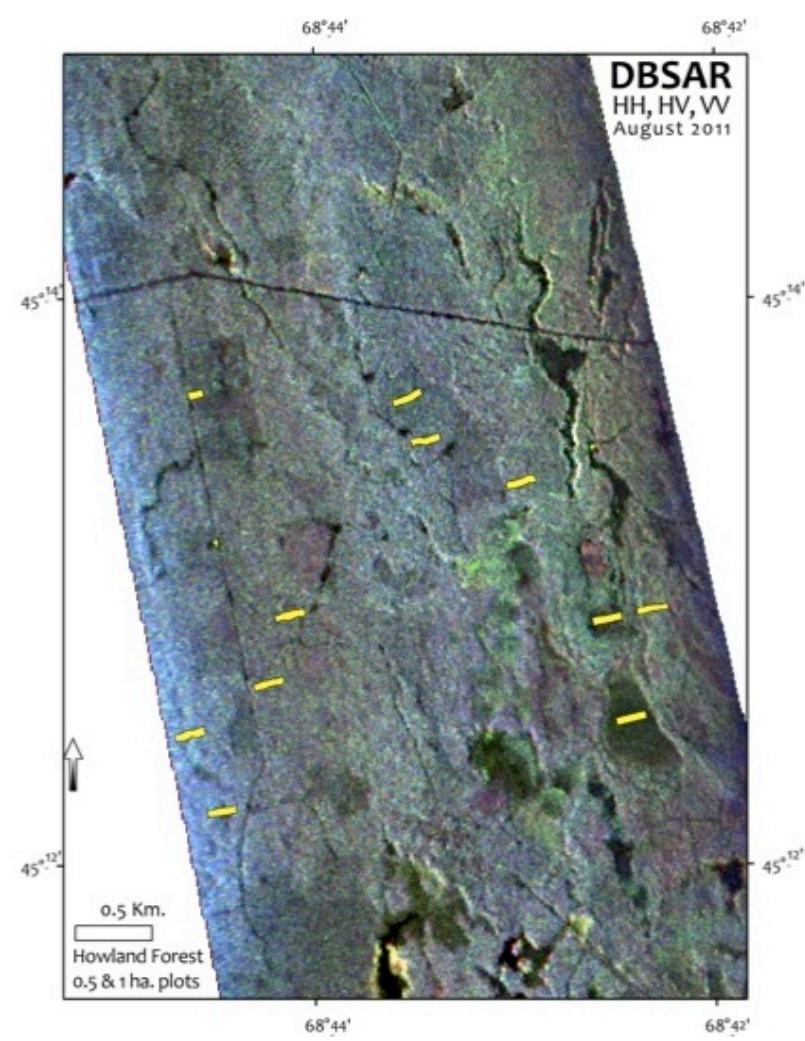

Figure 2 RGB composite of DBSAR over Howland, Maine. HH is shown in Red, HV in Green and VV in Blue.

Figure 3 shows an example flight path and CAR image over Bartlett, New Hampshire. Unlike any ground based BRDF measuring instrument, which characterizes BRDF over an area no larger than tens of meters in diameter, CAR can survey the BRDF characteristics of a region on the order of kilometers in diameter.

A complete circular orbit by the aircraft, defined by two solar disks in the image, allows the CAR to image the surface and sky in all viewing zenith and azimuthal angles, and covers an area defined by a diameter of $2-4 \mathrm{~km}$ on the surface. Note that in the backscattering direction (between the solar discs), the surface looks brighter than the forward direction (surface below the solar disc). 


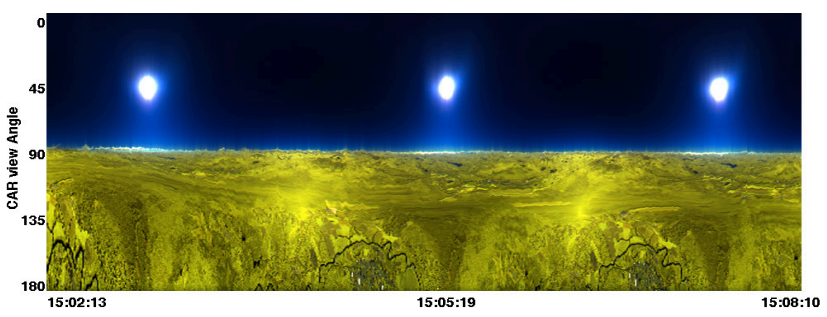

Figure 3 Quicklook CAR image of Bartlett Forest in all zenith and azimuth angles. In this RGB quicklook image, $R=1.036 \mu \mathrm{m}, G=0.870 \mu \mathrm{m}$ and $B=0.472 \mu \mathrm{m}$.

\section{CONCLUSIONS}

The Eco3D SAR, Lidar and Radiometer data represents a comprehensive multisensor data set over diverse and well-characterized forest sites. In addition to helping to develop new processing algorithms and methodologies for radar and lidar data, we anticipate that we will gain significant knowledge that will aid development and utilization of the next generation of sensors that add the $3^{\text {rd }}$ dimension to analysis of forest carbon and structure.

\section{REFERENCES}

Gatebe, C.K., E. Wilcox, R. Poudyal, J. Wang, 2011: Effects of ship wakes on ocean brightness and radiative forcing over ocean, In: Geophysical Research Letters, 38(L17702), September

Gatebe, C.K.,, J. J. Butler, J. W. Cooper, M. Kowalewski, and M. D. King, 2007: Characterization of scanning radiometers from laboratory measurements. Submitted to Appl. Opt. 46(31), 7640-7651.

Gatebe, C.K.,, J. J. Butler S. Platnick, G. T. Arnold, E. F. Vermote and B. Schmid, 2003: Airborne spec- tral measurements of surface-atmosphere anisotropy for several surfaces and eco- systems over southern Africa. J. Geophys. Res., 108, doi:10.1029/2002JD002397.

Goodale, C. L., Apps, M. J., Birdsey, R. A., et al. (2002). Forest carbon sinks in the northern hemisphere. Ecological Applications, 12, 891899.

Houghton, R. A., Hall, F. G., \& Goetz, S. J. (2009). Importance of biomass in the global carbon cycle, Journal of Geophysical Research, Biogeosciences VOL. 114, G00E03. doi:10.1029/2009JG000935.
Hall, F.G., Bergen, K., Blair, J.B., Dubayah, R., Houghton, R., Hurtt, G., Kellndorfer,J., Lefsky, M., Ranson, J., Saatchi, S., Shugart H.H., Wickland, D. (2011) Characterizing 3D vegetation structure from space: Mission requirements. Remote Sensing of the Environment. 115, 2753-2775

Le Toan, T., Beaudoin, A., Riom, J., \& Guyon, D. , 1992, Relating forest biomass to SAR data. IEEE Transactions on Geoscience and Remote Sensing, $30(2), 403-411$.

Lyapustin, A., C.K. Gatebe, R. Kahn, R. Brandt, J. Redemann, P. Russell, M.D. King, C. A. Pedersen, S. Gerland, R. Poudyal, A. Marshak, Y. Wang, C. Schaaf, D. Hall, A. Kokhanovsky, 2010: Analysis of Snow BRF from ARCTAS Spring-2008 Campaign, In: Atmos. Chem. Phys.(10), 4359-4375.

Rincon, Rafael F.; Vega, Manuel; Buenfil, Manuel; Geist, Alessandro; Hilliard, Lawrence; Racette, Paul; "DBSAR's First Multimode Flight Campaign," Synthetic Aperture Radar (EUSAR), 2010 8th European Conference on , vol., no., pp.1-4, 7-10 June 2010

Rincon, R. F.; Vega, M. A.; Buenfil, M.; Geist, A.; Hilliard, L.; Racette, P.; 2011A, "NASA's LBand Digital Beamforming Synthetic Aperture Radar," Geoscience and Remote Sensing, IEEE Transactions on, vol.49, no.10, pp.3622-3628, Oct. 2011 doi: 10.1109/TGRS.2011.2157971URL:

Rincon,R, T. Fatoyinbo, G. Sun, K. J. Ranson, M. Perrine, M. Deshpande, Q. Bonds, 2011, The EcoSAR P-band SAR Synthetic Aperture Radar, Proc. IEEE Int. Geosci. Rem. Sens. Symp., July 25-29, 2011, Vancouver, Canada.

Román, M., C. K. Gatebe, C. B. Schaaf, and M. D. King, 2010. Characterization of Surface Directional Reflectance Properties over the US Southern Great Plains during the 2007 CLASIC Experiment. Remote Sensing of Environment, doi:10.1016/j.rse.2011.04.012, 115, 2184-2203.

Stern Review on the economics of climate change (2008). Science marketing, freepost. The Edinburgh Building, Cambridge: Cambridge University Press CB2. http://www. cambridge.org/9780521700801 